IRA-International Journal of Education \&

Multidisciplinary Studies

ISSN 2455-2526; Vol.17, Issue 02 (Q2, 2021)

Pg. no. 61-68.

IRA Academico Research

\title{
A Brief Review of the Studies of Teacher Talk in Second Language Classrooms
}

\section{Xiaochun Wu}

School of Foreign Studies, Yangtze University, Hubei, 434023 PRC China.

Type of Work: Peer Reviewed.

DOI: 10.21013/jems.v17.n2.p3

DOI URL: https://dx.doi.org/10.21013/jems.v17.n2.p3

\section{How to cite this paper:}

Wu, X. (2021). A Brief Review of the Studies of Teacher Talk in Second Language Classrooms. IRA-International Journal of Education \& Multidisciplinary Studies (ISSN 2455-2526), 17(2), 61-68. DOI: https://dx.doi.org/10.21013/jems.v17.n2.p3

(C) IRA Academico Research.

(c) EY-No 4.0 International License subject to a proper citation to the publication source of the work.

Disclaimer: The scholarly papers as reviewed and published by IRA Academico Research are the views and opinions of their respective authors and are not the views or opinions of IRA Academico Research. IRA Academico Research disclaims any harm or loss caused due to the published content to any party.

IRA Academico Research is an institutional publisher member of Publishers International Linking Association Inc. (PILA-CrossRef), USA. IRA Academico Research is an institutional signatory to the Budapest Open Access Initiative. Hungary advocating the open access of scientific and scholarly knowledge. IRA Academico Research is a registered content provider under Open Access Initiative Protocol for Metadata Harvesting (OA/-PMH).

The journal is indexed \& included in WorldCat Discovery Service (USA), CrossRef Metadata Search (USA), WorldCat (USA), OCLC (USA), Open J-Gate (India), EZB (Germany) Scilit (Switzerland), Airiti (China), Bielefeld Academic Search Engine (BASE) of Bielefeld University, Germany, PKP Index of Simon Fraser University, Canada. 


\section{ABSTRACT}

This paper systematically reviews the studies of second language teacher talk in language classrooms firstly from the perspective of framework and then from three categories-linguistic function, medium-oriented function, procedural and regulative function. Next, a critical review of the relevant literature in China will be presented with the help of the tool Citespace. Through the comparison of studies at home and abroad, it is of significance to enhance the research in primary and secondary schools in China and consider the frameworks of teacher talk given by domestic authoritative scholars and look deep into teachers' discourse awareness and competence. Additionally, there are still many fields that researchers have not paid attention to, such as language selection and conversion, language ability, other time of teacher talk (play time; silence), lesson type (listening and speaking, reading and writing) etc.

Keywords: teacher talk; language classrooms; second language; teacher talk framework

\section{Introduction}

Anton Semyonovich Makarenko, a Soviet educator, says that the effects of the same teaching method maybe 20 times different because of teacher talk. Generally speaking, the kind of language used by the teacher for instruction in the classroom is known as teacher talk (TT). For this term, Longman Dictionary of Language Teaching and Applied Linguistics defines it as "that variety of language sometimes used by teachers when they are in the process of teaching". According to Rod Ellis (1985), second language teacher talk is the special language that teachers use when addressing second language (L2) learners in the classroom. Teacher talk has 7 characteristics: 1) the teacher's speech speed seems to be a little slower; 2) the teacher's thinking pauses more frequently and longer; 3) the pronunciation is clearer and clearer; 4) the selected vocabularies are simpler; 5) the degree of subordination is lower (that is, the less use of subordinate sentences); 6) there are more straightforward and declarative sentences than interrogative sentences; 7) the teacher's self-repetition is more frequent (Chaudron C., 1988).

Language is the most important teaching tool for teachers and teachers' speech styles and changes will have a profound impact on teaching effects (Jeremy Harmer, 1998). Relevant research started in the 1950s in western countries and began in the late 1990s in China. On top of that, researches in this field grow rapidly and have a critical role in improving the quality of language teaching and promoting teacher development. Rod Ellis (1985) divides the studies of teacher talk into two types: those that investigate the type of language that teachers use in language classrooms and those that investigate the type of language they use in subject lessons. In this paper, I propose to have a review of the studies that investigate the first type, specifically, language that teachers use in second language classrooms, firstly from the perspective of teacher talk framework and then from the perspective of empirical studies in the three categories of linguistic function, medium-oriented function, procedural and regulative function.

\section{A Review of Frameworks of Teacher Talk in Second Language Classrooms}

The frameworks of teacher talk, based on the combination of past research results, play a key role in the study of teacher talk in language classrooms, giving guidance for future studies such as discourse coding. For instance, Flanders (1961) puts forward the FIAC framework (Flanders Interaction Analysis Categories), dividing 
classroom speech acts into ten categories from three dimensions: teacher talk, student talk and other speech acts (such as silence). Later, Moskowitz (1971), based on the FIAC framework, proposes the FLINT framework (Foreign Language Interaction), subdividing teacher talk into twelve categories, including processing emotion, praise or encouragement, humor, using students' ideas, verbally repeating students' responses, questions, providing information, correcting mistakes, instruction, guiding drills, criticism of students' behavior and criticism of students' responses. Sinclair and Coulthard (1975) divide teacher talk into five levels: lesson, transaction, exchange, move and act. More significantly, based on the research, they propose the transmission mode of education: IRE (Initiation-Response-Evaluation), which was later changed to IRF (Initiation-Response-Follow up). Teacher talk is particularly evident in these two transmission modes so some researchers choose to compare their research results with these two modes like Xu and Ying (2002). Hall and Walsh (2002) argue that classroom talk mainly has three pragmatic functions: linguistic function, medium-oriented function, procedural and regulative function, followed by some researchers such as Ma and Liu (2013) in their article to classify and discuss relevant literature. In the following discussion in the $3^{\text {rd }}$ part, the explanation of these three functions will be presented with a review of some empirical articles from these three aspects. Though scholars have made great contributions to the improvement of frameworks, most of these studies have no consideration for the cross-linguistic applicability of these frameworks for analyzing foreign language (FL) teachers' target language (TL)/the first language(L1) use in contexts where FL instruction is offered in a range of different languages according to Kim S. H. O. \& Elder C.(2005) who develop the FLAATT framework (Functional Language Alternation Analysis of Teacher Talk) to allow a cross-linguistic comparison (detailed introduction in the $3^{\text {rd }}$ part).

Of course, some Chinese scholars have also put forward the frameworks of language teacher talk, such as Kang and Chen (2011). Based on the corpus research, they find that the past studies have ignored some functions of teacher talk such as scaffolding. In their new framework, there are four categories at the macro level: language input, implementation of teaching, classroom management and social communication, under which there are twelve dimensions respectively at the micro-level: demonstration, using students' discourse; direct explanation, initiation, leading in, prompt, question change, recognition, evaluation, direct error correction, corrective feedback, comment, development, clarification of the request, confirmation and verification; meta-instructions, instructions, nominations, summonses, incentives, and concluding remarks; turn marks, understand and verification, and maintaining discipline; conversation. In addition, Zhu Yan (2016) puts forward a multi-dimensional evaluation framework for the effectiveness of foreign language classroom discourse, including the consistency between classroom activities and teaching objectives, teacher discourse, student discourse, interactive participation forms, meaning/form-oriented turn and discourse structure. What's more, based on the theory of Vygotsky's zone of proximal development and scaffolding theory, Zheng Xinmin et al. (2019) put forward the interaction interface of "discourse-discourse" "discourse-emotion" "discourse-meaning" "discourse-value" "discourse-activity" as the scaffolds for English teaching and a four-in-one teacher's classroom discourse construction system. Nonetheless, it's a pity that many researchers still carry out the studies based on the frameworks from western countries, for which Ma and Liu (2013) argue that the frameworks of language teacher talk given by domestic authoritative scholars in China should be taken into consideration.

\section{A Review of Empirical Studies of Language Teacher Talk}

Hall and Walsh (2002) divide classroom talk into three categories based on pragmatic functions: linguistic function, medium-oriented function, procedural and regulative function. Firstly, the linguistic function means 
that classroom talk is a style code for the comprehensible language input and output of second language acquisition, helping learners to have authentic and understandable language input and output under different contexts. According to Ma and Liu (2013), its research field contains basically the amount of teacher talk (as seen in Chaudron, 1988; Zhao, 1998; etc.) and more specifically, phonetics, vocabulary, grammar, text as well as mixed types(as in $\mathrm{Hu}, 2003$; etc.). From my point of view, however, this function should also include the research about different phrases and sentence patterns like a question, instruction, feedback, restatement, marker and so on.

Three cases in point are the studies of Zhang and Liu (2010), Dong (2019) and Jiang (2020). Zhang and Liu (2010) have done interesting research about markers in language teacher talk. Based on the corpus, their study makes a significant test on the frequency of markers used by Chinese and foreign second language teachers and makes a qualitative-comparative analysis of the reasons for the different use of markers. Findings suggest that more than half of middle school English teachers in China used spoken markers normally; about one-third of teachers used less while one-tenth of teachers are overused. The research reveals that the diversity, accuracy and appropriateness of the markers of Chinese language teachers are significantly different from those of foreign language teachers and the authors have given detailed interpretation of different marker usage. This study also provides guidance for teachers to correct themselves and help them to find out the deficiencies in their oral expression, which have important implications for the professional development of English teachers. Another case is from Jiang (2020). The research adopts Spencer-Oatey's Rapport-management Theory as the analytical framework and uses discourse analysis to analyze how EFL teachers utilize various kinds of meta-discourse resources to construct dynamic identity in the classroom, to maintain the teacher's and students' face, and to realize the equality and association rights between the teacher and students for building teacher-student rapport. Based on conversation analysis, Dong (2019) focuses on question-response sequences in academic micro-contexts, and examines a teacher's use of questions within the EFL classroom, following SETT (Self-Evaluation of Teacher Talk) procedures, critically evaluates and relates the teacher's questions and students' responses to samples of authentic interactions. Findings indicate that the L2 classroom is a dynamic and complex series of inter-related micro-contexts, in which meaning is constructed and negotiated by both teachers and learners. The interaction under each class mode is driven and promoted by different types of questions, through which a variety of pedagogical goals are accomplished, including passage comprehension, language use, and critical thinking. In this process, opportunities for learning are also jointly increased by the teacher's extended wait-time, direct repair, and feedback. All of these suggest that appropriate use of questions can create an atmosphere that is conducive to learning and is likely to promote learner involvement.

Secondly, the medium-oriented function refers to the negotiation of meaning, knowledge construction and language function development. In the second language acquisition, negotiation of meaning is often used to refer to the interactive adjustment made by teachers and students in order to eliminate their communicative barriers. Cases are Kim and Elder (2005), Csomay E. (2007), etc. Take the study of Kim and Elder (2005) as an example. They examined the language choices made by 7 native-speaker (English) teachers in foreign language (FL) classrooms of Japanese, Korean, German and French in five New Zealand secondary schools. The results show that the participants differed markedly from one another not only in the amount of target language(TL) used but also in the pedagogic functions they used most frequently and in the language (TL or English) they chose for these functions. There was a tendency by most teachers to avoid complex interactions in the TL, limiting the potential for intake and real communication on the part of the students. Implications are drawn for research and teacher education. They also contribute to the framework of teacher talk: a multiple-category coding system entitled "Functional Language Alternation Analysis of Teacher Talk" (FLAATT), which is 
developed expressly to allow a cross-linguistic comparison of the relationship between teachers' language choices and particular pedagogic functions. What can't be ignored is that the research about the linguistic function and the medium-oriented function are both closely related to teaching function and teaching effects.

Thirdly, the procedural and regulative function means that teacher talk has the function of organizing, managing and regulating classroom activities and language behaviors. There were many studies about the procedural and regulative function in the western countries, such as Christie F., 2002, but fewer studies in China. For instance, from the perspective of Bernstein's teaching discourse theory, Liu and Zhang (2010) adopt the corpus research method to analyze the conventional discourse in middle school English classes in China. Through quantitative analysis of teachers' directives, they find that in the class, teachers used more direct, less polite and more mandatory classroom instructions. The classroom has not yet realized the transformation from teacher-centered to student-centered advocated by the discourse of foreign language curriculum and teaching reform in China.

\section{Reflection on the Relevant Research in China}

Relevant research started in the late 1990s in China, with Zhao's research (1998) on the amount of teacher talk published. It is worth mentioning that Ma and Liu (2013) has had a critical review of the past relevant research. They point out the main problems in this research field, including the problems about research theories, research methods, research objects and research contents. Besides, they also give suggestions for the study of English teacher talk in China: to have systematic research of English teacher talk; to broaden the study of the characteristics of teacher talk as an inter-language; to correct evaluation of IRF interaction mode; to improve empirical research methods; to strengthen the theory of English teacher talk and have a better combination with practice.

With the help of the tool Citespace and then reading the articles in detail, I also have some critical thoughts. There are about one hundred and fifty relevant key articles from 1998 to 2020 in the CNKI (SCI, CSSCI, PKU, EI and CSCD). Based on the statistics, keywords in recent years' research of language teacher talk are teacher talk, classroom talk, teacher talk, discourse analysis, case study, foreign language class, college English class, college English teacher, target learner, strategy, sign language. Moreover, there are eleven keyword clusters: teacher talk, class type, questioning talk, reference question, corpus, Krashen, foreign language class, relevance theory, output optimization, discourse quantity. According to the data, the $2^{\text {nd }}$ keyword cluster (questioning talk) shows that most of the research focuses on the linguistics features (similar to the result of Ma and Liu, 2013); the $3^{\text {rd }}$ keyword cluster (reference question) and the $8^{\text {th }}$ keyword cluster (output optimization) indicate that research pays more and more attention to the development of students; the $4^{\text {th }}$ keyword cluster (corpus) reveals that Corpus is the trend of research tools in this field. There are, however, some problems. For example, research of the amount of teacher talk still occupies a large part; studies mainly happen in university classrooms; researchers tend to carry out the study and analyze based on foreign theories or frameworks like language environment theory and IRF in Xu and Ying (2002), interaction hypothesis and Swain output hypothesis in Liu (2006), input and interaction theory in $\mathrm{Hu}$ (2007) and Krashen input hypothesis in Li (2007). Thus, based on the suggestions from Ma and Liu (2013), I think that it is of significance to strengthen the study of language teacher talk in primary and secondary schools and consider the frameworks of language teacher talk given by Chinese authoritative scholars like Kang and Chen (2011). More importantly, there are still many fields that researchers have not paid attention to, such as language selection and conversion, language ability (such as language fluency), other speech time (play time; silence), lesson type (listening and speaking, reading and writing) etc. 
Furthermore, the study of language teacher talk in foreign countries has gone, instead of study in various types, deeply into language teachers' discourse awareness and competence (such as Kim S. H. O. \& Elder C., 2005), which is yet lacking in China.

In addition, there are plenty of topics needed to be considered in this field. For one thing, the studies focus on teachers but the depth of domestic research in this field needs to be expanded. Teachers' language ability (including language background, fluency and other factors), discourse ability and cognitive ability should also be paid attention to. The application analysis of discourse can not be separated from considering the changes of people, things, places and times. For example, Li (2007), by using the discourse analysis method, compares the interaction patterns of the two types of college English classes, one instructed by native speakers of English, the other by Chinese teachers of English. It has been found that TST (Teacher Student-Teacher) pattern occurs more frequently in the classes taught by Chinese teachers of English. No significant difference has been found between the two types of classes in terms of the total frequency of the moves. Moreover, it has revealed that the exchanges initiated by students promote students' participation in classroom activities. The study has implications both for the organization of English teaching classes and for the employment of native English speakers as college English teachers in China.

For another thing, we cannot neglect other factors such as the influence of students. Henzl's study of teacher talk (1979, cited from Ellis R., 1985) has shown that the teachers adjust their speech rate in accordance with the listeners' proficiency. That is, teacher talk is dynamically tailored to learners' needs, affording them increasingly richer input as they develop. Li and Zhao (2016) argue that the qualified output generated in the classroom interaction relies on the negotiation of meaning. Some English teachers, however, tend to avoid negative feedback during the course of negotiation, which is not helpful for output production and leads to fossilization as well. Teachers ought to have a proper perception of "classroom interaction", make full use of negotiation devices, and thus help students generate qualified output. Meanwhile, advanced technology should be applied and the form of output should be diversified.

Additionally, researchers need to consider the impact of teaching contexts and the output of teacher talk. Some researchers look more carefully at the different types of lesson types such as writing class (like Ewert D. E., 2009). For instance, Lv and Wang (2013) employ both qualitative and quantitative methods to conduct a reflective analysis regarding Teaching Resource Platform in college English teachers' classroom discourses in terms of the amount of teacher talk, teachers' questions and feedback. The results indicate that this student-centered model helps promote effective negotiable interaction, plays an important role in heuristic teaching and development of second language acquisition, paving the way to the realization of the model of a flipped classroom.

Interestingly, now there appears a new perspective for the research: critical discourse analysis. That is, based on the critical discourse analysis of teacher talk, researchers want to find out the unfair issues, aimed at improving the relationship between teachers and students so as to better promote the development of students.

Under the curriculum reform in China, it is worth noting that with the introduction of the Core Competence of English Discipline in 2017, the research field of English teaching in primary and secondary schools has undergone changes. As a result, the study of language teacher talk can also be considered from the perspective of the Core Competence of English Discipline which includes four parts: language ability, learning ability, cultural awareness and thinking quality. 


\section{Conclusion}

Through the overall review of the studies of second language teacher talk from the perspective of framework and then from three categories, followed by the comparison of studies at home and abroad, it is of significance to enhance the research in primary and secondary schools in China and consider the frameworks of teacher talk given by domestic authoritative scholars in China. Furthermore, there are still many topics that researchers can pay attention to, such as language selection and conversion, language ability, other time of teacher talk (play time; silence), lesson type (listening and speaking, reading and writing) etc. There is a lack of research deep into language teachers' discourse awareness and competence in China.

\section{References}

[1]. Chaudron C. Second Language Classrooms: Research on Teaching and Learning [M]. Cambridge: Cambridge University Press, 1988.

[2]. Christie F. Classroom Discourse Analysis: A Functional Perspective [M]. Bloomsbury Publishing, 2002.

[3]. Csomay E. A Corpus-based Look at Linguistic Variation in Classroom Interaction: Teacher Talk versus Student Talk in American University Classes [J]. Journal of English for Academic Purposes, 2007, 6(4):336-355.

[4]. Dong Ming. Teacher Questioning in EFL Micro-contexts: A SETT Conversation Analysis Approach [J].Foreign Language and Literature, 2019,35(04):145-152.

[5]. Ellis R. Understanding Second Language Acquisition [M]. Shanghai: Shanghai Foreign Language Education Press, 1985.

[6]. Ewert D. E. L2 Writing Conferences: Investigating Teacher Talk [J]. Journal of Second Language Writing, 2009, 18(4): 251-269.

[7]. Flanders N. A. Analyzing Teacher Behavior [J]. Educational Leadership, 1961, 19(3).

[8]. Hall J. K., Walsh M. Teacher-student Interaction and Language Learning [J]. Annual Review of Applied Linguistics, 2002:22.

[9]. Hu Qingqiu. A Contrastive Analysis of English Classroom Discourse between Chinese and Foreign Teachers-a Case Study [J].Foreign Language Learning Theory and Practice, 2007(01): 32-37.

[10].Hu Xuewen. Features and Functions of Teacher Talk [J]. Shandong Foreign Language Teaching, 2003(03):39-43.

[11].Jiang Hui. A Study on EFL Teachers' Classroom Metadiscourse from the Perspective of Rapport-management Theory [J].Foreign Language Research, 2020(04):45-50.

[12].Jeremy Harmer. How to Teach English [M]. Foreign Language Teaching and Researching Press, 1998.

[13].Kang Yan, Chen Xiaotang. A New Framework of the Functions of Foreign Language Teachers' Classroom Discourse [J].Foreign Language Learning Theory and Practice, 2011,3(3):7.

[14].Kim S. H. O., Elder C. Language Choices and Pedagogic Functions in the Foreign Language Classroom: a Cross-linguistic Functional Analysis of Teacher Talk [J]. Language Teaching Research, 2005, 9(4):355-380.

[15].Moskowitz G. Interaction Analysis-A New Modern Language for Supervisors [J]. Foreign Language Annals, 2010, $5(2): 211-221$.

[16].Li Suzhi. Comparing Interaction Patterns in the Classes of Native English Teachers and Chinese Teachers [J]. Journal of PLA University of Foreign Languages, 2007(02):34-39.

[17].Li Ye, Zhao Dongmei. Negotiation of Meaning and Output Optimization of College English Class [J]. Journal of Northeast Normal University (Philosophy and Social Sciences), 2016(03): 131-135.

[18].Liu Xuehui.EFL Student-teachers' Classroom Talk: Data-basing, Analysis and Application [J].Technology Enhanced Foreign Language Education, 2006(05):41-45. 
[19].Liu Yongbing, Zhang Huiping. A Corpus-based Study of Regulative Discourse in Chinese Secondary School English Language Classrooms [J].Foreign Languages and Their Teaching, 2010(04):14-18.

[20].Lv Tingting, Wang Yuchao. An Empirical Study on Teacher Talk in College English Classroom: Based on Teaching Resource Platform [J].Foreign Languages in China, 2013,10(04):69-77.

[21].Ma Yi, Liu Yongbing. Analysis of English Classroom Talk in China [J].Foreign Language Learning Theory and Practice, 2013, V02(002):42-47.

[22].Sinclair J. M., Coulthard R. M. Towards an Analysis of Discourse: The English Used by Teachers and Pupils [J]. Tesol Quarterly, 1975, 11(2).

[23].Xu Erqing, Ying Huilan. A Study of New College English Classroom Discourse [J].Foreign Languages and Their Teaching,2002(03):24-27.

[24].Zhang Huiping, Liu Yongbing. A Corpus-based Study of Middle School English Teachers' Classroom Discourse Markers [J].Foreign Language Teaching and Research, 2010, 042(005):356-363.

[25].Zhao Xiaohong. Investigation and Analysis of Teachers' Discourse in College English Reading Class [J].Foreign Language World, 1998(02):3-5.

[26].Zheng Xinmin, Xu Jianbo, Yao Yang. The Micro Level of High School English Teacher Development: The Moves of a Productive Classroom Discourse [J].Foreign Language Research, 2019(02):68-72.

[27].Zhu Yan, Yang Xiaohong, Su Dingfang. A Multi-faceted Framework on Effectiveness of Foreign Language Classroom Discourse: A Tentative Analysis of Representative Teaching Scenarios in the 4th SFLEP National Foreign Language Teaching Contest [J].Foreign Language Education, 2016,37(01):53-57. 